\title{
Evaluation of the forecast reliability of site effect for regional mining tremors
}

\author{
Józef Dubiński, Krystyna Stec*, and Grażyna Holeczek \\ Central Mining Institute, Katowice, Poland
}

\begin{abstract}
It is obligatory for Polish underground mines of hard coal and copper to prepare long-term exploitation projects for $2-5$ years. All the natural hazards, including seismic ones, that may occur have to be taken into account in such projects. In the case of mining seismicity the forecast of site effect plays an important role. To recognize the reliability of this forecast for strong regional mining tremors special methodology was used. The peak ground velocity and peak ground acceleration, recorded after the occurrence of a regional tremor by surface seismometric network stations, were compared with the distribution of the forecast values of these parameters determined for similar seismic energy. Differences between these values are the basis for the evaluation of the reliability of the forecast site effect. The practical implementation was presented with the tremor of seismic energy $E=5 \cdot 10^{8} \mathrm{~J}\left(M_{L}=3.63\right)$ which occurred on $18^{\text {th }}$ January 2018 . The small value $\Delta P G V_{\text {Hmax }}(4 \%)$ of the difference between the recorded $P G V_{\text {Hmax }}{ }^{\text {rec }}$ and the forecast values $P G V_{H \max }{ }^{p r}$ confirms that the measurement values correlate well with the forecast values. The difference value $\triangle P G A_{H 10}$ for the peak ground acceleration equals $31 \%$ showing a worse correlation with the forecast data.
\end{abstract}

Keywords: mining tremors, site effect, velocity, acceleration

\section{Introduction}

Mining tremors are dynamic phenomena caused by underground mining operations. They occur as a result of violently displaced, fractured or caved-in rock mass layers. In the Upper Silesian Coal Basin (USCB) there is a distinct group of tremors which are directly associated with mining face advance, so-called exploitation tremors, of seismic energy $10^{2} \leq E<10^{7} \mathrm{~J}$ (local magnitude $\left.M_{L} 0.1 \leq M_{L}<3.2\right)$ and a group of strong tremors of $E \geq 10^{8} \mathrm{~J}\left(M_{L} \geq 3.2\right)$ so-called regional tremors [1]. Regional tremors are associated with mining operations over a greater area, covering one or several mines, and the occurrence of tectonic zones or other geological structures in the area of mining operations (folds, synclines, overlaps) [2]. Continuous seismographic measurements, conducted by the Upper Silesian Seismological Network (USSN) of the Central Mining Institute and mine networks, enable the observation

\footnotetext{
* Corresponding author: kstec@gig.eu
} 
of all the mining tremors occurring in the USCB, the location of their foci and the determination of their energy [3].

The USSN database of $1977-2017$ contains 62,650 tremors of seismic energy $E \geq 10^{5} \mathrm{~J}$. The collected data concerning the energy and the number of mining tremors in given energy classes is presented in Table 1. In the USCB, to determine the value of local magnitude, the dependence of $\log E=1.8+1.9 \log M_{L}$ (where: $E$ - seismic energy in J, $M_{L}$-local magnitude) is applied.

Table 1. List of mining tremors in the Upper Silesian Coal Basin, 1977 - 2017.

\begin{tabular}{|lr|r|}
\hline \multicolumn{2}{|c|}{ Energy $E, \mathrm{~J} /$ Local magnitude $M_{L}$} & $\begin{array}{c}\text { No. of } \\
\text { tremors }\end{array}$ \\
\hline $10^{5} \leq \mathrm{E}<10^{6}$ & $1.7 \leq \mathrm{M}_{\mathrm{L}}<2.2$ & 53.260 \\
\hline $10^{6} \leq \mathrm{E}<10^{7}$ & $2.2 \leq \mathrm{M}_{\mathrm{L}}<2.7$ & 8.433 \\
\hline $10^{7} \leq \mathrm{E}<10^{8}$ & $2.7 \leq \mathrm{M}_{\mathrm{L}}<3.3$ & 851 \\
\hline $10^{8} \leq \mathrm{E}<10^{9}$ & $3.3 \leq \mathrm{M}_{\mathrm{L}}<3.8$ & 88 \\
\hline $10^{9} \leq \mathrm{E}<4 \cdot 10^{9}$ & $3.8 \leq \mathrm{M}_{\mathrm{L}}<4.2$ & 18 \\
\hline & Total & $\mathbf{6 2 . 6 5 0}$ \\
\hline
\end{tabular}

Regional tremors, despite their rarity (approx. 1-3 every year), resemble weak earthquakes. They have a strong influence on surface infrastructure and people's well-being. They often cause fear and significant discomfort. The phenomena often result in damaged buildings and property (Photos 1). In the USCB, as a result of mining tremors, a few hundred buildings were damaged [4].
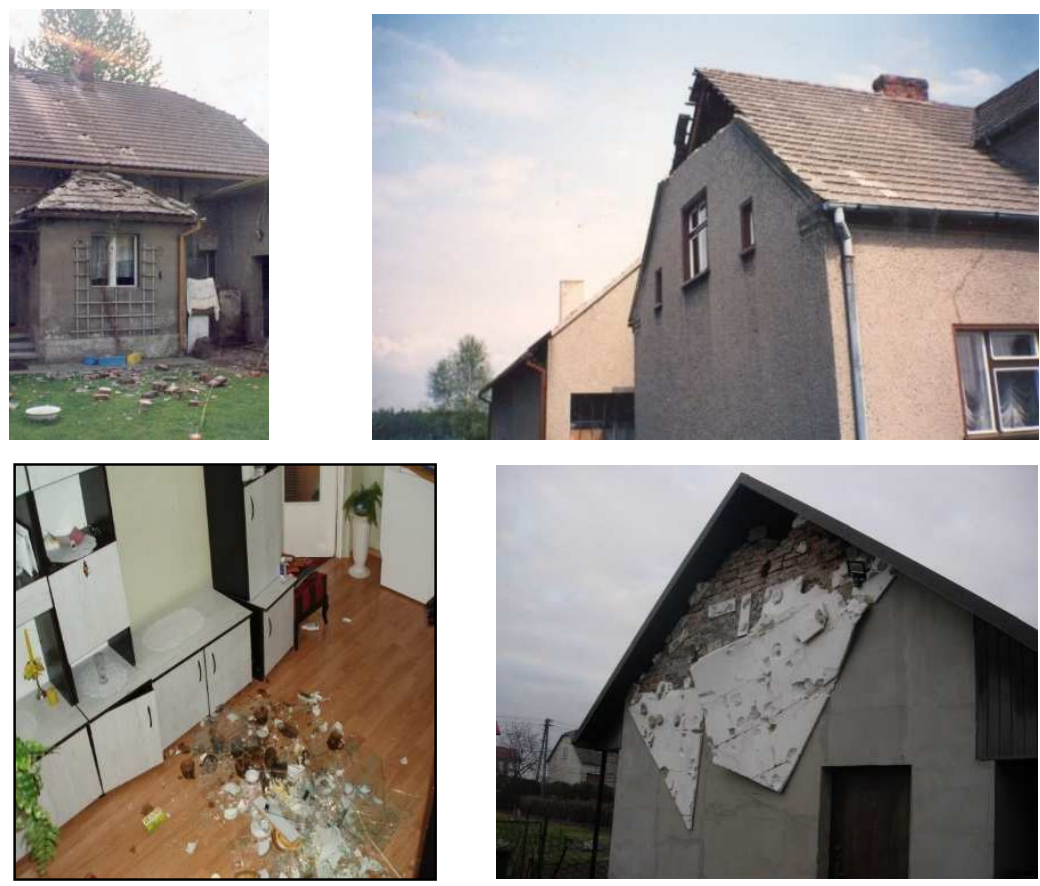

Photo 1. Damage in buildings after a tremor of seismic energy $\mathrm{E}=1 \cdot 10^{9} \mathrm{~J}, \mathrm{M}_{\mathrm{L}}=3.8$ ).

The aforementioned seismicity means that protecting surface infrastructure is a significant problem. When strong tremors of regional nature occur, the intensity of ground motion caused by a tremor becomes an important parameter. Basic parameters employed to determine the intensity of tremors are amplitudes of peak ground velocity $(P G V)$, peak 
ground acceleration $(P G A)$ and the duration of the tremors. The exploitation tremors usually have relatively higher vibration velocity and acceleration, yet only in the epicentral zone, and short duration of their vibrations, thus their intensity is sensed only within the epicentral zone. Regional tremors have a distinctly longer seismic wave (lower frequencies of the dominant vibrations), longer duration and a greater area of high vibration intensity. Developing seismic forecasts for Polish mining basins is one of the significant elements of mining projects made for 2 to 5 year horizons. They include forecasting the places of the occurrence of mining tremors and, first of all, strong regional seismic phenomena together with their forecasted seismic energy and the distribution of ground motion parameters. Moreover, selected places on the surface, which require special protection, are constantly monitored providing data on the actual values of the ground motion parameters. This enables the evaluation of the reliability of these forecasts in reference to the parameters of surface vibrations determining their intensity. It has to be emphasised that the reliability of the forecasts is crucial for construction work planned in areas subjected to the dynamic influence of mining operations. On their basis local authorities determine the conditions for planned buildings, including additional measures to protect the objects against damage caused by seismic phenomena.

\section{Forecasting the seismic energy of regional tremors}

Forecasts of the parameters of site effect induced by regional rock mass tremors, first of all contain the evaluation/forecast of the maximum seismic energy which may occur when the mining project is realised, at a given probability of tremor occurrence. The energy is determined with the use of statistical distributions based on the catalogues of tremors which occurred in similar geological and mining conditions. The mathematical models applied here are asymptotic extreme distributions called Gumbel distribution functions. Their significant advantage is the fact that they make relatively general assumptions of the type of data which can be described in such a way. For the calculations made for the article, concerning forecasts of the occurrence of regional tremors, of the foci located in local tectonic zones, Gumbel distribution function III was assumed.

Gumbel distribution function III is expressed with the following equation:

$$
G(x)=\operatorname{Exp}\left[-\left(\frac{W-x}{W-u}\right)^{B}\right]
$$

where:

$x=\log E-$ random variable describing the seismic energy logarithm,

$W, B, u$-distribution parameters.

Parameter $W$ is the upper limit in which random variable $x$ can assume. Hence it is limited to the top values, which follow the seismometric observations and the physics of the phenomenon (level of stress in the observed area). The most important parameter characterising seismic risk, when statistical distribution function $G(x)$ is assumed to be known, is seismic hazard $R D(x)$ which determines the occurrence probability of the tremors with logarithm of seismic energy $x$ or greater during $D$ time intervals. Seismic hazard is expressed with the equation:

$$
R D(x)=1-G(x)^{\mathrm{D}}
$$

The conducted research into the evaluation of the repeatability of strong regional rock mass tremors were based on the catalogue of tremors of seismic energies $110^{2} \leq E<6 \cdot 10^{8} \mathrm{~J}$ $\left(1.7 \leq M_{L}<3.7\right)$, which occurred between 1 January 2007 and 8 November 2017. The 
catalogue contained 80,652 events. The monthly distribution of the maximum seismic energy of the tremors is presented in Fig. 1, while Fig. 2 presents the Gumbel distribution function III and the measurement data. The calculated parameters of the distribution function $G(x)$ were applied to assess seismic risk $R D(x)$, i.e. the occurrence probability of a tremor of energy $E \geq 10^{\mathrm{x}}$ $\mathrm{J}$ during the 3 -year period of the planned mining exploitation $(2018-2020)$. The data is presented in Table 2 and Figure 3.

To forecast the parameters of site effect, following the USCB rules, the maximum seismic energy is determined which, with a $10 \%$ probability, will not be exceeded. As the table and the figure show, in the analysed $10 \%$ probability area for 3 years, seismic energy of $E=5 \cdot 10^{8} \mathrm{~J}$ $\left(M_{L}=3.63\right)$ will not be exceeded. The locations of potential foci of regional tremors were associated with greater faults and pillars for mine workings in the vicinity of planned coal longwalls.

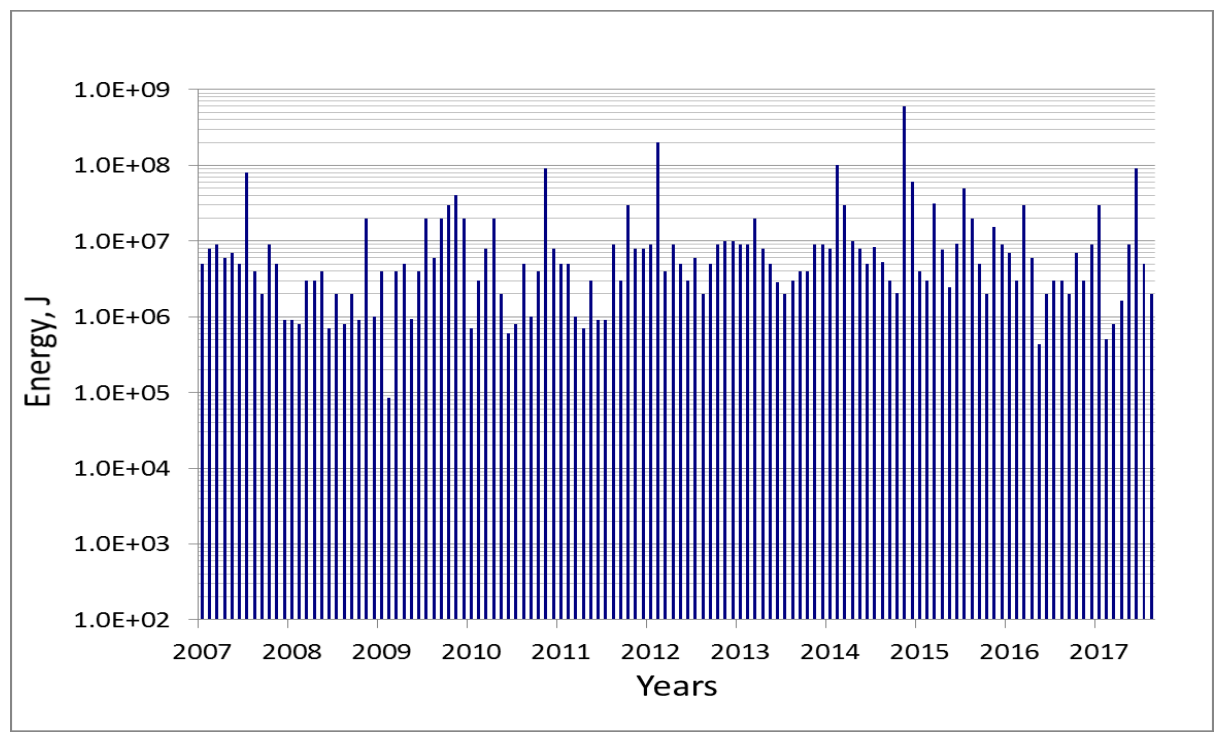

Fig. 1. Monthly maximum energy tremors distribution for the period from 1 Jan 2007 to 8 Nov 2017.

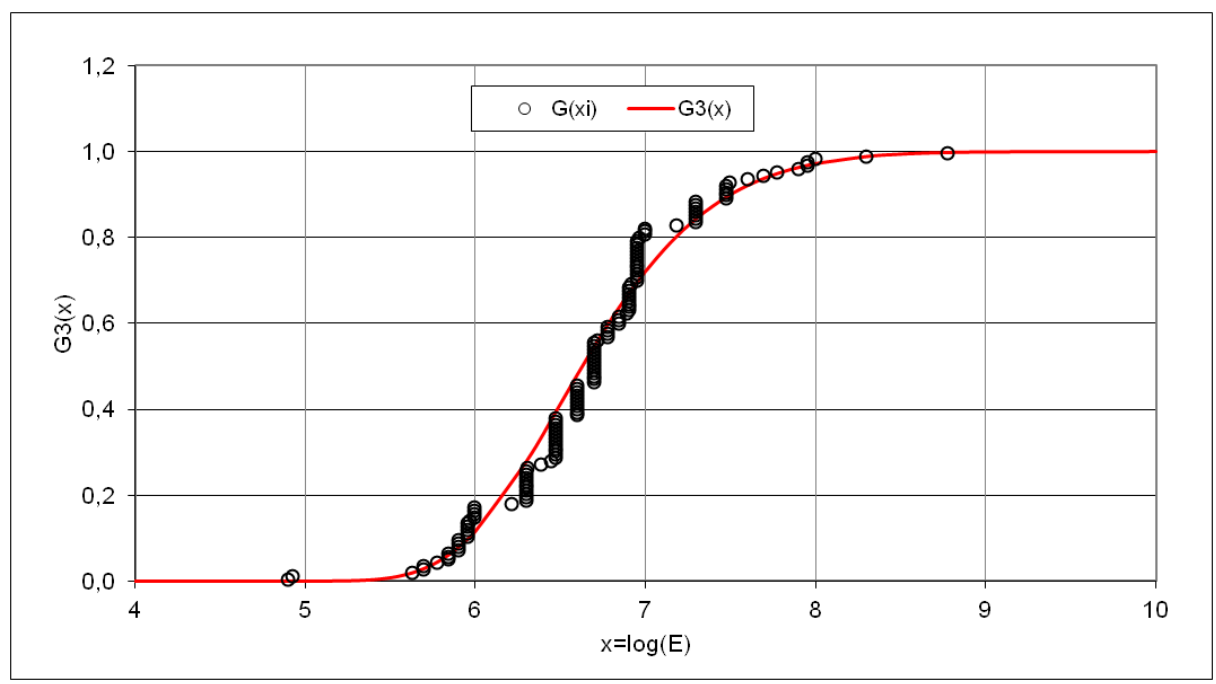

Fig. 2. Gumbel distribution function III (red line) and measurement data (circles) for the period from 1 Jan 2007 to 8 Nov 2017. 
Table 2. Occurrence probability the forecast seismicity over a 3-year period of the planned mining exploitation $(2018-2020)$.

\begin{tabular}{|c|c|c|c|c|c|c|c|c|c|c|c|}
\hline $\begin{array}{c}\text { Seismic } \\
\text { energy, J }\end{array}$ & $1 \cdot 10^{7}$ & $5 \cdot 10^{7}$ & $6 \cdot 10^{7}$ & $7 \cdot 10^{7}$ & $8 \cdot 10^{7}$ & $9 \cdot 10^{7}$ & $1 \cdot 10^{8}$ & $2 \cdot 10^{8}$ & $3 \cdot 10^{8}$ & $4 \cdot 10^{8}$ & $5 \cdot 10^{8}$ \\
\hline $\begin{array}{c}\text { Probability } \\
\%\end{array}$ & 100.0 & 90.00 & 84.63 & 79.12 & 73.74 & 68.66 & 63.93 & 33.86 & 20.70 & 13.93 & 9.99 \\
\hline
\end{tabular}

Seismic risk

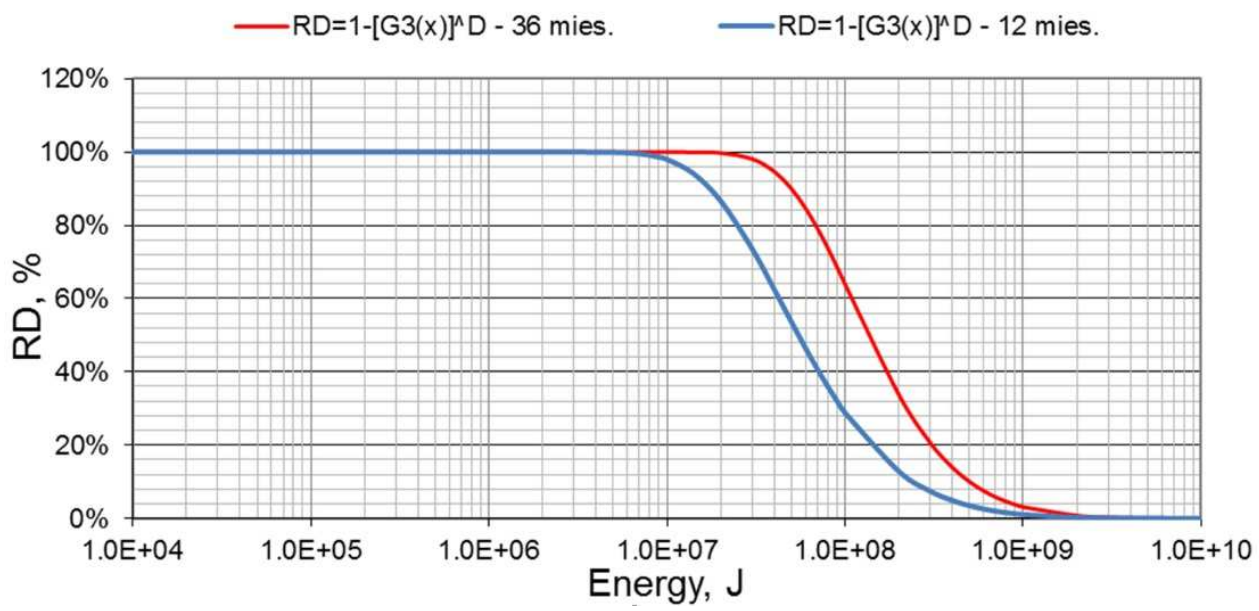

Fig. 3. Seismic risk of regional tremors for the exploitation planned for 3 years (red line) and one year (blue line) in coal mine.

\section{Evaluation of the reliability of the forecast isoseism of ground motion velocity and acceleration based on measurement data}

Regional scale empirical dependences were employed to forecast parameters of ground motion for the planned mining operations $[5,6]$. They are based on records from numerous seismometric stations located in the USCB. They determine the dependence of the resultant peak ground velocity $P G V_{\text {Hmax }}$ or peak ground acceleration $P G A_{H 10}$ of up to $10 \mathrm{~Hz}$ on the seismic energy of the tremors and epicentral distance, considering the types of ground defined in EUROCODE 8 (PN-EN 1998-1).

The research employed attenuation relations for peak ground velocity amplitude $P G V_{\text {Hmax }}$ and peak ground acceleration amplitude $P G A_{H 10}$ in the ground rock [5]. According to the EUROCODE 8 standard it is ground type A.

$$
\begin{aligned}
& \log \left(P G V_{H \max }\right)=0,209 \log (E)-0,33 R-\log (R)-0,814 \\
& \log \left(P G A_{H 10}\right)=0,223 \log (E)-0,041 R-\log (R)+0,586
\end{aligned}
$$

where:

$P G V_{\text {Hmax }}$ - peak ground velocity, $\mathrm{mm} / \mathrm{s}$,

$P G A_{H 10}$ - peak ground acceleration of frequency up to $10 \mathrm{~Hz}, \mathrm{~mm} / \mathrm{s}^{2}$

$E$ - seismic energy of tremor, J,

$R$ - epicentral distance, $\mathrm{m}$.

For the forecast, in this instance, the maximum seismic energy of tremors of $E=5 \cdot 10^{8} \mathrm{~J}$ $\left(\mathrm{M}_{\mathrm{L}}=3.63\right)$, which may occur in the analysed area in $2018-2020$ with a $10 \%$ probability, 
maps of distribution of predicted peak ground velocity $P G V_{H \max }^{p r}$ isoline (Fig. 4) and predicted peak ground acceleration $P G A_{H 1}{ }^{p r}$ isoline (Fig. 5) were drawn.

In January 2018, in the analysed area, a regional tremor of seismic energy of $E=5 \cdot 10^{8} \mathrm{~J}$ $\left(M_{L}=3.63\right)$ occurred and this was recorded by four surface seismometric stations. Their location with recorded value is shown in Figures 4 and 5. The distributions isolines consider the trend of tectonic zones and the distribution of subsoil amplification coefficient in this area presented in Fig. 6.

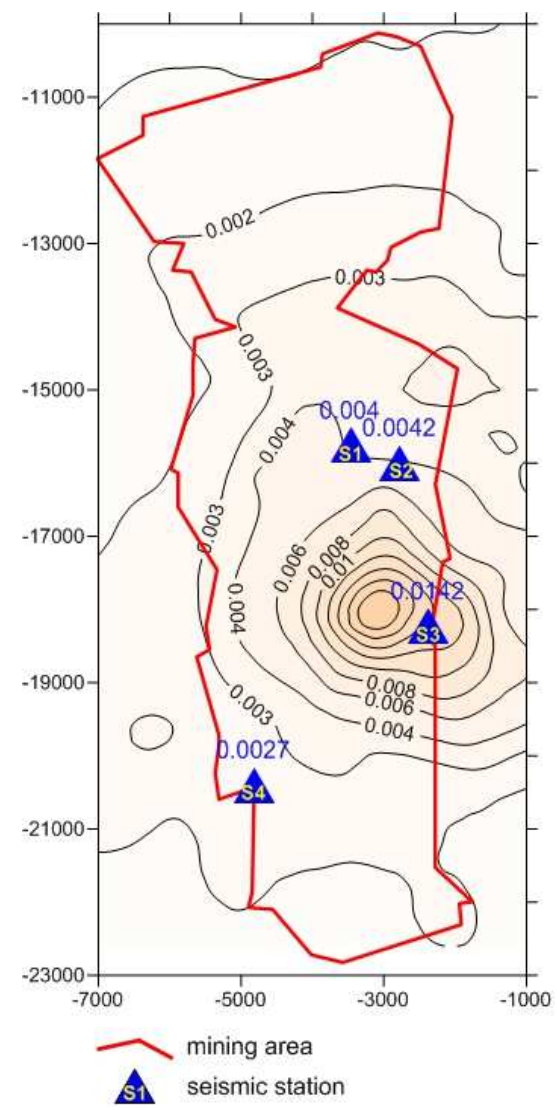

Fig. 4. Distribution of the forecast $P G V_{H \max }{ }^{r e c}$ and recorded peak ground velocity $P G V_{H \max }{ }^{p r}$.

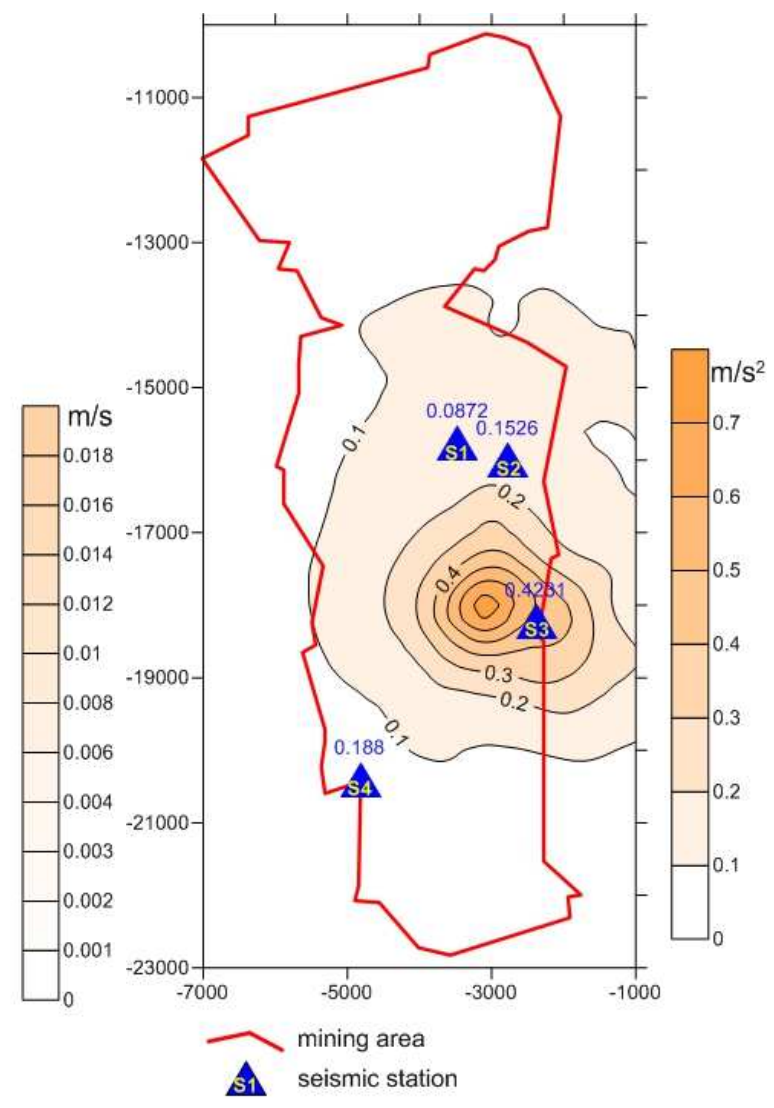

Fig. 5. Distribution of the forecast $P G A_{H 10^{r e c}}$ and recorded peak ground acceleration $P G A_{H 1} 0^{p r}$.

The reliability of the forecast site effect for regional mining tremors was analysed through comparing the values of the peak ground velocity $P G V_{\text {Hmax }}{ }^{\text {rec }}$ and the peak ground acceleration $P G A H 10^{r e c}$, recorded by the stations of the surface seismometric network after a strong regional tremor of seismic energy of $5 \cdot 10^{8} \mathrm{~J}\left(\mathrm{M}_{\mathrm{L}}=3.63\right)$, with forecast values of the distribution of velocity $P G V_{\text {Hmax }}{ }^{p r}$ and acceleration $P G A_{H I}{ }^{p r}$ for the same seismic energy.

$$
\begin{gathered}
\Delta P G V_{\text {Hmax }}=P G V_{\text {Hmax }}^{\text {rec }}-P G V_{\text {Hmax }}^{p r} \\
\Delta P G A_{H 10}=P G A_{H 10^{r e c}}-P G A_{H 10^{p r}}
\end{gathered}
$$

where:

$\triangle P G V_{H \max }, \triangle P G A_{H 10}$ - difference which the forecast reliability is based on. 


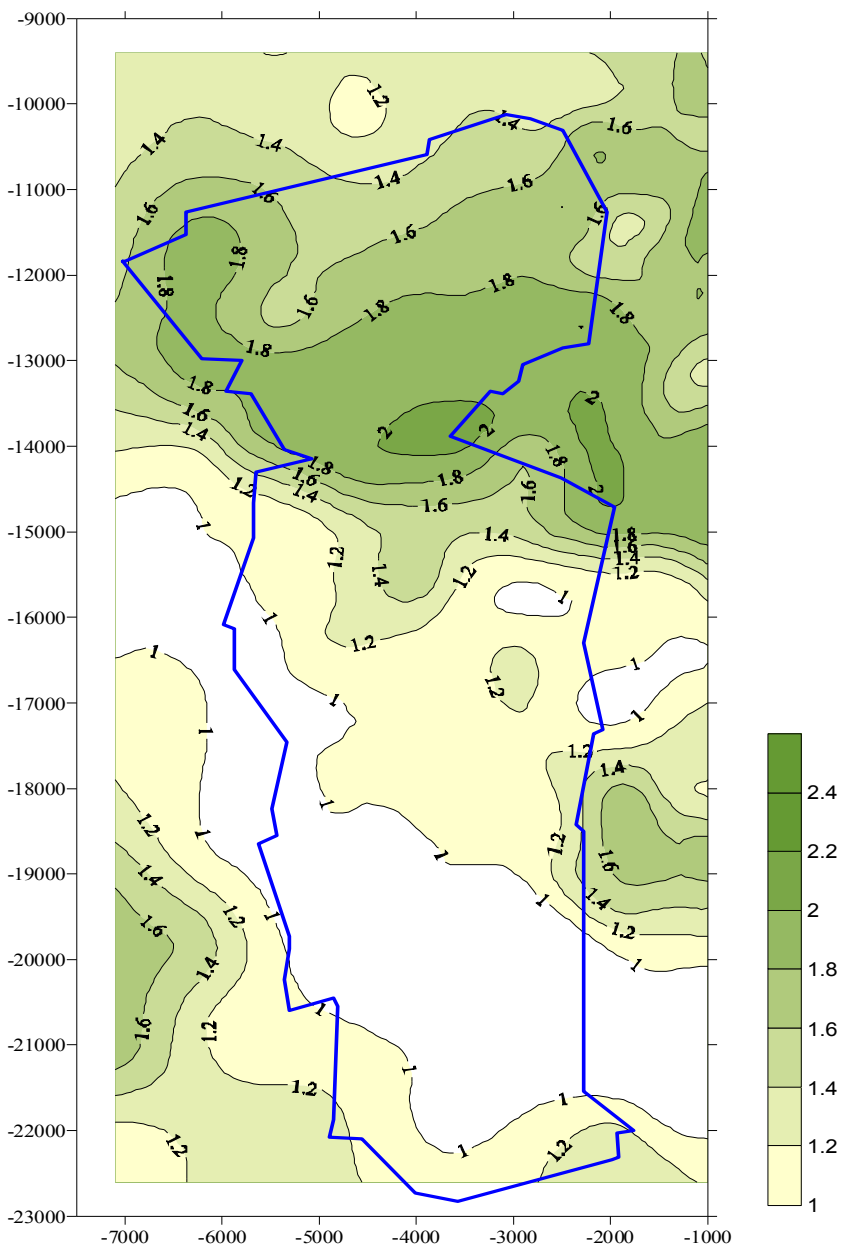

Fig. 6. Distribution of subsoil amplification coefficient.

In Table 3, columns 5 and 8 show the percentage of the difference between the recorded and the forecast ground motion velocity and accelerations, which indicates the quality and reliability of the forecast side effect, caused by strong mining tremors of regional origin. It shows that, the average difference between the forecast and the really recorded values for the ground motion velocity $\triangle P G V_{H \max }$ is $4 \%$. For the ground motion acceleration $\triangle P G A_{H 10}$ the difference is much higher and equals $31 \%$. This means that ground motion velocity is a much better and much more reliable forecast parameter.

Table 3. Recorded and forecast ground motions velocity and acceleration for a tremor of seismic energy $E=5 \cdot 10^{8} \mathrm{~J}\left(M_{L}=3.63\right)$.

\begin{tabular}{|c|c|c|c|c|c|c|c|}
\hline $\begin{array}{c}\text { Station } \\
\text { no. }\end{array}$ & $\begin{array}{c}\text { Epicentral } \\
\text { distance, } \\
\mathrm{m}\end{array}$ & $\begin{array}{c}P G V_{\text {Hmax }}^{\text {rec }} \\
\mathrm{m} / \mathrm{s}\end{array}$ & $\begin{array}{c}P G V_{\text {Hmax }}{ }^{p r} \\
\mathrm{~m} / \mathrm{s}\end{array}$ & $\begin{array}{c}\Delta P G V_{\text {Hmax }} \\
\%\end{array}$ & $\begin{array}{c}P G A_{H 10^{r e c}} \\
\mathrm{~m} / \mathrm{s}^{2}\end{array}$ & $\begin{array}{c}P G A_{H 10^{p r}} \\
\mathrm{~m} / \mathrm{s}^{2}\end{array}$ & $\begin{array}{c}\Delta P G A_{H 10} \\
\%\end{array}$ \\
\hline 1 & 2 & 3 & 4 & 5 & 6 & 7 & 8 \\
\hline $\mathrm{S} 1$ & 2282 & 0.004 & 0.0039 & 3.0 & 0.087 & 0.127 & 46 \\
\hline $\mathrm{S} 2$ & 2032 & 0.0042 & 0.0041 & 3.2 & 0.153 & 0.132 & 13 \\
\hline $\mathrm{S} 3$ & 807 & 0.0142 & 0.0138 & 2.9 & 0.423 & 0.463 & 9 \\
\hline $\mathrm{S} 4$ & 2965 & 0.0027 & 0.0025 & 6.5 & 0.188 & 0.080 & 57 \\
\hline
\end{tabular}




\section{Conclusion}

In Polish underground mines of hard coal and copper ore, it is compulsory to prepare longterm exploitation projects that determine their spatial distribution in a 2 - to 5-year time horizon. These projects take into account all natural hazards, including seismic ones.

The seismic forecast is important both because of the threat of rockbursts and the impact of ground motion on the surface environment. It is particularly important in reference to strong seismic events of a regional nature.

The small value $\triangle P G V_{\text {Hmax }}(4 \%)$ of the difference between the recorded $P G V_{H \max }{ }^{\text {rec }}$ and the forecast values $P G V_{H \max }{ }^{p r}$ parameters confirms that the measured values correlate well with the values of the forecast ground motion velocity; this strong correlation proves the accuracy of the methodology used to forecast site effect for strong regional tremors and the reliability of the forecast results.

The greater value $\triangle P G A_{H 10}(31 \%)$ of the difference between the recorded $P G A_{H 10}{ }^{r e c}$ and the forecast values of $P G A_{H 1}{ }^{p r}$ parameters shows worse correlation and distinctly little reliability of the forecast results obtained with this parameter.

\section{References}

1. K. Stec, Characteristic of seismic activity of the Upper Silesian Coal Basin in Poland, GEOPHYS J INT 168, 2, 757-768 (2007) doi.org/10.1111/j.1365-246X.2006.03227.x

2. M. Kozłowska, B. Orlecka-Sikora, Ł. Rudziński, S. Cielesta, G. Mutke Atypical evolution of seismicity patterns resulting from the coupled natural, human-induced and coseismic stresses in a longwall coal mining environment, INT J ROCK MECH MIN 86, 5-15 (2016) doi: 10.1016/j.ijrmms.2016.03.024

3. R. Patyńska, K. Stec, Regional Rockburst Indicator for structural units of Upper Silesian Coal Basin, STUD GEOTECH MECH 39, 3, 27-37 (2017) doi:10.1515/sgem2017-0027

4. G. Mutke, J. Chodacki, L. Muszyński, S. Kremers, R. Fritschen, Mining Seismic Instrumental Intensity Scale MSIIS-15 - verification in coal basins. AIMS 2015 - Fith Int. Symp.: Mineral Resources and Mine Development. RWTH Aachen University. 14, 551-560. (ISBN 978-3-941277-22-9) (2015)

5. J. Chodacki, New Ground Motion Prediction Equation for Peak Ground Velocity and Duration of Ground Motion for Mining Tremors in Upper Silesia, ACTA GEOPHYS 64, 6, 2449-2470 (2016) doi.org/10.1515/acgeo-2016-0109 